\title{
28 Research Square \\ Detrimental Health Relationship Between Blood Cadmium and the Red Blood Cell Folate Level
}

\section{Bo-kai Wang}

Tri-Service General Hospital, National Defense Medical Center

Wei-Liang Chen ( $\nabla$ weiliang0508@gmail.com )

Tri-Service General Hospital, National Defense Medical Center

\section{Research Article}

Keywords: cadmium, Cd, folate, micronutients

Posted Date: November 4th, 2021

DOI: https://doi.org/10.21203/rs.3.rs-1026253/v1

License: (c) (i) This work is licensed under a Creative Commons Attribution 4.0 International License. Read Full License 


\section{Abstract}

Background and Aims: Increasing studies have demonstrated the association between heavy metal pollution and micronutrients, especially folate. However, the relationship between cadmium and folate remains rarely discussed. In this study, we aim to explore the potential correlation between cadmium and folate in human population, and highlight the possible mechanism of cadmium impacting on human health.

Method and Results: We utilized the National Health and Nutrition Examination Survey(NHANES) 20172018 data with 5690 participants in this study. Multivariable linear regression models were adopted to investigate the serum cadmium levels and RBC folate concentration. Gender differences in this correlation was also explored. A significant reverse relationship was found between serum cad-mium and RBC folate, either in male or female.

Conclusions: A negative relationship between serum cadmium levels and levels of RBC folate either in male or female group in the U.S adult population was found in this study. Nevertheless, due to the general limitations of the NHANES data, as a cross-sectional study, further prospective investigation is needed to discover the causality of cadmium in folate status, and to determine whether or not the folate supplement have a beneficial influence against heavy metal toxicities.

\section{Introduction}

Along with the flourishing industrialization, the heavy metal pollution contributed by them have become a health issue in urban populations. More than ten kinds of metallic chemical elements or metalloids are included in heavy metal pollution[1]. Among them, cadmium(Cd) plays an important role in affecting human health. Cd can result in various major adverse effects involving kidney disease, bone disease, lung disease, and several cancer[2]. Furthermore, in recent studies, cadmium was found to cause excess oxidative stress, dysregulation of the miRNA expression, modulation of cellular signaling pathways, deregulation of cell proliferation, and apoptosis resistance[3]. The effects of heavy metal pollution on micronutrients have also been reported increasingly [4-6].

Folates, known as vitamin B9, are water-soluble vitamins, which are not able to be synthesized by human cells and naturally presenting in food. They take a crucial part of one-carbon metabolism, involved in the synthesis of DNA, RNA, and proteins. In addition, evidence has also suggested that folates have antioxidant, anticancer, cardiovascular, and neuroprotective effects[7]. Red blood cell(RBC) folate is one of biomarkers to represent folate levels in the individual. It is specific in expression of tissue folate levels, which wouldn't be affected by temporary changes in dietary intake[8], as a result, being an useful surrogate of long-term folate status instead of serum folate concentration.

A rising number of researches disclose the robust relationship between toxic heavy metal and homocysteine metabolism[9]. Homocysteine is an intermediate amino acid in conversion of methionine and cysteine, and the accumulation of it will cause adverse heathy effects. As a necessary cofactor, 
folate have an essential part in homocysteine metabolism. However, the role of heavy metal pollution, especially cadmium, in folate status in human remained undefined. Hence, this article aimed to investigate the connection between cadmium levels and levels of folate with the data from the National Health and Nutrition Examination Survey (NHANES) from 2017 to 2018.

\section{Materials And Methods}

\section{Ethics statement}

All materials in this study were obtained out of the National Health and Nutrition Examination Survey (NHANES) database, which was authorized by the National Center for Health Statistics (NCHS) of the Centers for Disease Control and Prevention (CDC). The NHANES database was approved by the NCHS Institutional Review Board(Protocol \#2018-01 and Continuation of Protocol \#2011-17) in accordance with the revised Helsinki Declaration. The informed consents had been completed before data collection procedures and extensive health examinations.

\section{Data source and participants}

The data was extracted from the NHANES since 2017 to 2018, which contained a comprehensive interview and a series of examination. The survey is a cross-sectional study executed by the National Center for Health Statistics (NCHS) of the Centers for Disease Control and Prevention (CDC), aiming to explore the health and nutritional status of non-institutionalized U.S. civilians. All details and information of NHANES are available on the website. We analyzed broad materials comprising of demographic data, questionnaire details, laboratory results, RBC folate levels, and heavy metal levels. Participants with missing associated information, or related covariates were excluded. Totally, 5690 participants were included in this study.

\section{Measurement of blood cadmium}

The blood cadmium levels were detected via an inductively coupled plasma mass spectrometry with dynamic reaction cell(ICP-DRS-MS) and the limit of detection for the blood cadmium was $1 \mu \mathrm{g} / \mathrm{L}$. In healthy unexposed adults, concentrations of blood cadmium are in the range of $0.1-4 \mu \mathrm{g} / \mathrm{L}$. In this study, the inter-assay coefficient of variation are $4.93 \%$.

\section{Measurement of red blood cell folate}

In NHANES, RBC folate was calculated from the whole blood folate concentration, which was detected in microbiological assays with inoculated medium containing Lactobacillus rhamnosus[10]. The whole blood folate concentration was evaluated by estimating the turbidity of the Lactobacillus rhamnosus' medium using the PowerWave X340 Microplate reader (Bio-Tek Instrument) with $590 \mathrm{~nm}$ wave. Next, whole blood folate concentration was adjusted by red blood cell volume, correcting for serum folate level, which was accessed by isotope-dilution high performance liquid chromatography/tandem mass spectrometry (LC-MS/MS). In this LC-MS method, five folate forms would be detected, including folic acid, 
tetrahydrofolate, 5-methyl-tetrahydrofolate, 5-formyl-tetrahydrofolate, and 5,10-methenyltetrahydrofolate[11]. Multi-rule quality control program was adopted in this study. The reference range of $\mathrm{RBC}$ folate is $505-2,490 \mathrm{nmol} / \mathrm{L}$. Besides, the inter-assay coefficient of variation is $5.1 \%$.

\section{Covariates}

Part of related variables, including age, gender, race/ethnicity, smoking status, and liver condition, were obtained by self-report. Smoked participants were identified whenever they self-reported smoked at least $100+$ cigarettes during their lifetime. Liver condition was classified through the question "Are you ever told having any liver condition?" Participants' platelet counts were measured by Beckman Coulter DxH-800 analyzer in the NHANES Mobile Examination Center. Urinary albumin levels were assessed using Fluorescein Immunoassay by Sequoia-Turner Digital Fluorometer, Model 450 by University of Minnesota. Other biochemistry profiles, including alanine transaminase(ALT), serum creatinine, serum total bilirubin, were attained with Roche Cobas 6000 analyzer performed by University of Minnesota. All the protocols were following the standardized procedures of $\mathrm{CDC}$ reference method, and were available on the NHANES websites.

\section{Statistical analysis}

The Statistical Package for the Social Sciences, version 18.0 (SPSS Inc., Chicago, IL, USA) Software was adopted in our all statistical investigation. Categorical variables were presented by their means and standard deviation(SD), whereas continuous variables were presented by their frequency counts and percentages. We analyzed categorical features with the Chi-square test, and continuous features with the Wilcoxon Rank sum test, respectively. Exploring the association between serum cadmium levels in tertiles with RBC folate concentrations using multivariable logistic regression models, an extended-model investigation was designed for covariate adjustment as follow: Model 1 was not adjusted for any variables; Model 2 was adjusted for age, sex and race/ethnicity; Model $3=$ Model $2+$ platelet count, urinary albumin, ALT, total bilirubin, and creatinine; Model 4 = Model $3+$ history of smoked. Gender difference in this association was also examined by multivariable logistic regression models. A two-sided $P$ value less than 0.05 was interpreted as statistically significant.

\section{Results}

\section{Heavy metal and RBC folate}

The association between circulating concentrations of heavy metal and RBC folate concentration of the 5690 enrolled participants is shown in Table 1. In fully adjusted model, the $\beta$ coefficient between lead, cadmium, mercury, manganese, selenium, and RBC folate were -18.278 (95\% Cl: -25.835 to -10.721 ; $p<0.001),-119.261$ (95\% Cl: $-210.556,-27.965 ; p=0.011),-2.745$ (95\% Cl: -5.513 to 0.022; $p=0.052), 4.401$ (95\% Cl: 2.416 to $6.387 ; p<0.001), 0.478$ (95\% Cl: 0.18 to $0.776 ; p=0.002)$, respectively. These finding demonstrated that lead and cadmium had significantly reverse correlation with RBC folate concentration, while manganese and selenium had significantly positive correlation with RBC folate concentration. 


\section{Demographic data of Study population}

Table 2 illustrates the demographic characteristics of the participants categorized by cadmium tertiles. The tertile-based cadmium level among the study population were: $<0.19 \mu \mathrm{g} / \mathrm{L}, 0.19-0.39 \mu \mathrm{g} / \mathrm{L}$, $>0.39 \mu \mathrm{g} / \mathrm{L}$, respectively. The participants with higher cadmium level seemed more likely to be woman and smoker. They tended to be older, and have higher levels of urinary albumin and creatinine, and lower levels of total bilirubin and platelet count. Besides, they seemed to have higher prevalence of liver condition(all, $p<0.05$ ).

\section{Relationships between levels of RBC folate and cadmium levels}

We examined the association between RBC folate and cadmium, and the result was shown in figure 1. In the tertiles-based multiple linear regression analysis, RBC folate levels in participants with T3 cadmium were significantly lower than those with $\mathrm{T} 1$ cadmium in all adjusted models. The $\beta$ coefficients between T3 cadmium group and T1 cadmium group in all models were $-6.517(95 \% \mathrm{Cl}:-26.539$ to $13.506 ; \mathrm{p}=0.052$ in model 1$),-42.649(95 \% \mathrm{Cl}:-62.872$ to $-22.426 ; \mathrm{p}<0.001$ in model 2$),-44.05(95 \% \mathrm{Cl}:-64.234$ to -23.866 ; $\mathrm{p}<0.001$ in model 3), and $-40.683(95 \% \mathrm{Cl}$ : -62.192 to $-19.174 ; \mathrm{p}<0.001$ in model 4 ), respectively. Furthermore, we also did subgroup analysis in different gender, which was shown in Table 3. The regression coefficients of the highest tertile compared with the base tertile in the totally adjusted model of the different genders were -58.941 (95\% Cl: -94.072 to $-23.81 ; p=0.001$ in male), and $-31.371(95 \% \mathrm{Cl}$ : -58.83 to $-3.911 ; p=0.025$ in female), respectively. Collectively, the above finding indicated that cadmium levels had a significantly negative correlation with levels of RBC folate, and these relationships were more evident when the cadmium levels became higher. In addition, these associations persisted whether in male population or in female population.

\section{Discussion}

In this study of the US general population, the most remarkable finding was that serum cadmium levels had an adverse relationship with levels of RBC folate. The association became stronger when the highest cadmium tertile was compared with the lowest cadmium tertile. Besides, gender differences had no effect on these significant relationships. Best of our knowledge, our research is the first report in investigating the relationship between cadmium levels and body folate status.

After reviewing the published articles, few studies explored the association between cadmium and folate. Only a multicenter prospective Korean research, containing 2171 participants, revealed serum folate levels in pregnant women were reversely associated with blood cadmium concentrations at late pregnancy[12]. Additionally, two small-scale studies reported that higher blood cadmium levels might be association with higher levels of serum homocysteine[13, 14]. In a cohort with 259 participants, Pollack et al. found that in healthy, premenopausal women, blood cadmium was correlated with increased homocysteine but this correlation was not strong after adjustment for corresponding confounding factors. A Chinese-population based study, containing 159 individuals, indicated that an increasing cadmium level could raise the probability of a surge in homocysteine level. Although the relationship 
between cadmium and homocysteine isn't robustly proven, there is still a positive trend. As we have known, lots of researches had illustrated that homocysteine levels are inversely related to serum folate[15-17]. In one systemic study, Ledda et al. had the similar result that exposure to heavy metal, including cadmium, is correlated with homocysteine levels or folate serum concentrations[9]. Besides, the role of red cell folate in presenting the individual's folate status is well demonstrated[8]. All of the abovementioned could extend the idea that cadmium levels might have an opposite effect on RBC folate levels, which is compatible with our finding. Unfortunately, the populations of abovementioned studies are all too narrow to apply their results to general population. Our investigation provides a more general and a large-scaler evidence in this issue.

Cadmium had been proven to cause numerus adverse effects on human via several pathways, including increasing oxidative stress, impairment of the antioxidant response, enzyme inactivation, and multiple organ damage[3]. However, the mechanism between cadmium and folate status is unclear, and we try to propose three possible hypothesis for it. First of all, cadmium was found to be absorbed via metal transporters in the intestinal, and it would accumulate in the intestinal as cadmium exposure increased[18]. On the other hand, folate is mainly absorbed from diet via intestinal, and oxidative stress might interfere gut microbiome, therefore, causes folate deficiency[19]. They imply that cadmium might cause gut damage via ROS generation, as a consequence, resulting in folate malabsorption. Second, $\mathrm{Cd} 2+$ is a predominant and competitive inhibitor of the enzyme[20], and it can bind to numerus protein with the sulfhydryl group(-SH), leading to protein inactivation. Cadmium might interfere the enzyme of the folate cycle, and it needs more studies to investigate the details. Last but not least, cadmium is proven to be carcinogenesis, and it can effect on several transcription factors, such as Activator Protein 1 (AP-1), Nuclear Factor-kappa B (NF-kB), and p53. Hence, uncontrolled cell growth and division will happen due to failure in control of the expression of protective genes[21]. It might increase the need for folate due to abnormally increasing cell proliferation, and this hypothesis requires more research to confirm it.

Several potential limitations should be considered in our study. First, NHANHES database is a crosssectional study. Consequently, a causal relationship between cadmium levels and folate status couldn't be determined only according to this one-off health check-up program, instead of to long-standing observation study. Second, the intake of folate wasn't analyzed in our study. Although dietary questionnaire used in the NHANES survey was documented, 24-hour dietary recall may not provide an indication of long-term diet nor an accurate representation of actual intake. Moreover, in spite of adjusting multiple potentially confounding factors, there may have been other residual effects from unadjusted confounding factors of the correlation between cadmium levels and folate status.

\section{Conclusion}

This study highlighted that a negative relationship between serum cadmium levels and levels of RBC folate either in male or female group in the U.S adult population. Such finding proposed the possible mechanism how cadmium influenced human body. Further prospective research is needed to explore the 
causality of cadmium in folate status, and to determine whether or not the folate supplement have a beneficial influence against heavy metal toxicities.

\section{Declarations}

\section{Author Contributions:}

Conceptualization, B.-K.W. and W.-L.C.; methodology, W.-L.C.; software, W.-L.C.; validation, B.-K.W. and W.L.C.; formal analysis, B.-K.W. and W.-L.C.; investigation, B.-K.W. and W.-L.C.; resources, W.-L.C.; data curation, B.-K.W. and W.-L.C.; writing-original draft preparation, B.-K.W.; writing-review and editing, B.K.W. and W.-L.C.; visualization, B.-K.W. and W.-L.C.; supervision, W.-L.C. All authors have read and agreed to the published version of the manuscript.

\section{Financial Support:}

No financial support was used for this study.

\section{References}

1. Briffa, J., E. Sinagra, and R. Blundell, Heavy metal pollution in the environment and their toxicological effects on humans. Heliyon, 2020. 6(9): p. e04691.

2. Järup, L. and A. Akesson, Current status of cadmium as an environmental health problem. Toxicol Appl Pharmacol, 2009. 238(3): p. 201-8.

3. Balali-Mood, M., et al., Toxic Mechanisms of Five Heavy Metals: Mercury, Lead, Chromium, Cadmium, and Arsenic. Front Pharmacol, 2021. 12: p. 643972.

4. Tiwari, A.K.M., et al., Effect of iron and folate supplementation on $\mathrm{Pb}$ levels in pregnant anemic women: a prospective study. Free Radic Res, 2020. 54(8-9): p. 662-669.

5. Luo, Y., et al., Maternal blood cadmium, lead and arsenic levels, nutrient combinations, and offspring birthweight. BMC Public Health, 2017. 17(1): p. 354.

6. Wang, G., et al., Association Between Maternal Exposure to Lead, Maternal Folate Status, and Intergenerational Risk of Childhood Overweight and Obesity. JAMA Netw Open, 2019. 2(10): p. e1912343.

7. Asbaghi, O., et al., Effects of Folic Acid Supplementation on Oxidative Stress Markers: A Systematic Review and Meta-Analysis of Randomized Controlled Trials. Antioxidants (Basel), 2021. 10(6).

8. Sobczyńska-Malefora, A. and D.J. Harrington, Laboratory assessment of folate (vitamin B(9)) status. J Clin Pathol, 2018. 71(11): p. 949-956. 
9. Ledda, C., et al., Exposure to Toxic Heavy Metals Can Influence Homocysteine Metabolism? Antioxidants (Basel), 2019. 9(1).

10. Cooper, B.A., Superiority of simplified assay for folate with Lactobacillus casei ATCC 7469 over assay with chloramphenicol-adapted strain. J Clin Pathol, 1973. 26(12): p. 963-7.

11. Fazili, Z., et al., A high-throughput LC-MS/MS method suitable for population biomonitoring measures five serum folate vitamers and one oxidation product. Anal Bioanal Chem, 2013. 405(13): p. 4549-60.

12. Kim, H., et al., Relationship between serum folate status and blood cadmium concentrations in pregnant women: Mothers and children's environmental health (MOCEH). Annals of Nutrition and Metabolism, 2013. 63: p. 809.

13. Pollack, A.Z., et al., Blood lead, cadmium and mercury in relation to homocysteine and C-reactive protein in women of reproductive age: a panel study. Environ Health, 2017. 16(1): p. 84.

14. Cai, R., et al., Effects of blood lead and cadmium levels on homocysteine level in plasma. Eur Rev Med Pharmacol Sci, 2017. 21(1): p. 162-166.

15. Selhub, J., et al., Vitamin status and intake as primary determinants of homocysteinemia in an elderly population. Jama, 1993. 270(22): p. 2693-8.

16. Robinson, K., et al., Low circulating folate and vitamin B6 concentrations: risk factors for stroke, peripheral vascular disease, and coronary artery disease. European COMAC Group. Circulation, 1998. 97(5): p. 437-43.

17. Vermeulen, E.G., et al., Effect of homocysteine-lowering treatment with folic acid plus vitamin B6 on progression of subclinical atherosclerosis: a randomised, placebo-controlled trial. Lancet, 2000. 355(9203): p. 517-22.

18. Ohta, H. and K. Ohba, Involvement of metal transporters in the intestinal uptake of cadmium. J Toxicol Sci, 2020. 45(9): p. 539-548.

19. Jose, S., P. Bhalla, and G.K. Suraishkumar, Oxidative stress decreases the redox ratio and folate content in the gut microbe, Enterococcus durans (MTCC 3031). Sci Rep, 2018. 8(1): p. 12138.

20. Pan, C., et al., Cadmium is a potent inhibitor of PPM phosphatases and targets the M1 binding site. Sci Rep, 2013. 3: p. 2333.

21. Valko, M., H. Morris, and M.T. Cronin, Metals, toxicity and oxidative stress. Curr Med Chem, 2005. 12(10): p. 1161-208.

\section{Tables}


Table 1. Association between circulating concentrations of heavy metal and RBC folate concentration.

\begin{tabular}{|c|c|c|c|c|c|c|c|c|}
\hline $\begin{array}{l}\text { Trace } \\
\text { elements }\end{array}$ & $\begin{array}{c}\text { Model 1 } \\
\beta \text { (95\% CI) }\end{array}$ & $p$ & $\begin{array}{c}\text { Model } 2 \\
\beta \text { (95\% CI) }\end{array}$ & $p$ & $\begin{array}{c}\text { Model } 3 \\
\beta \text { (95\% CI) }\end{array}$ & $p$ & $\begin{array}{c}\text { Model } 4 \\
\text { B (95\% } \\
\text { CI) }\end{array}$ & $p$ \\
\hline $\begin{array}{l}\text { Lead } \\
\text { (ug/dL) }\end{array}$ & $\begin{array}{c}2.092(-5.182, \\
9.366)\end{array}$ & 0.573 & $\begin{array}{l}-19.109 \\
(-26.659 \\
-11.558)\end{array}$ & $<0.001$ & $\begin{array}{l}-19.033 \\
(-26.563 \\
-11.503)\end{array}$ & $<0.001$ & $\begin{array}{l}-18.278 \\
(-25.835 \\
-10.721)\end{array}$ & $<0.001$ \\
\hline $\begin{array}{l}\text { Cadmium } \\
\text { (ug/L) }\end{array}$ & $\begin{array}{c}-119.409 \\
(-203.556, \\
-35.263)\end{array}$ & 0.006 & $\begin{array}{l}-112.071 \\
(-197.129, \\
-27.013)\end{array}$ & 0.01 & $\begin{array}{c}-113.361 \\
(-199.393, \\
-27.33)\end{array}$ & 0.01 & $\begin{array}{c}-119.261 \\
(-210.556, \\
-27.965)\end{array}$ & 0.011 \\
\hline $\begin{array}{l}\text { Mercury } \\
\text { (ug/L) }\end{array}$ & $\begin{array}{c}-1.577 \\
(-4.424,1.27)\end{array}$ & 0.278 & $\begin{array}{c}-2.561 \\
(-5.324 \\
0.202)\end{array}$ & 0.069 & $\begin{array}{c}-2.456 \\
(-5.219 \\
0.307)\end{array}$ & 0.081 & $\begin{array}{c}-2.745 \\
(-5.513 \\
0.022)\end{array}$ & 0.052 \\
\hline $\begin{array}{l}\text { Manganese } \\
\text { (ug/L) }\end{array}$ & $\begin{array}{c}2.007(0.01 \\
4.003)\end{array}$ & 0.049 & $\begin{array}{c}4.666 \\
(2.703, \\
6.63)\end{array}$ & $<0.001$ & $\begin{array}{c}4.559 \\
(2.577 \\
6.541)\end{array}$ & $<0.001$ & $\begin{array}{l}4.401 \\
(2.416 \\
6.387)\end{array}$ & $<0.001$ \\
\hline $\begin{array}{l}\text { Selenium } \\
\text { (ug/L) }\end{array}$ & $\begin{array}{c}0.51(0.2, \\
0.821)\end{array}$ & 0.001 & $\begin{array}{c}0.486 \\
(0.188, \\
0.783)\end{array}$ & 0.001 & $\begin{array}{c}0.479 \\
(0.181, \\
0.778)\end{array}$ & 0.002 & $\begin{array}{l}0.478 \\
(0.18 \\
0.776)\end{array}$ & 0.002 \\
\hline
\end{tabular}

Abbreviations: RBC, red blood cell; CI, confidence interval.

$\beta$ coefficients were interpreted as change of RBC folate concentration for each increase in different trace elements concentration.

Adjusted covariates: Model 1 = Unadjusted model; Model $2=$ Adjusted for age, sex and race/ethnicity; Model $3=$ Model $2+$ platelet count, urinary albumin, ALT, total bilirubin, and creatinine; Model $4=$ Model $3+$ history of smoked (defined as ever smoked at least 100 cigarettes in a lifetime).

Table 2. Characteristics of study participants by tertiles of serum cadmium concentration $(\mu \mathrm{g} / \mathrm{L})$

\begin{tabular}{|c|c|c|c|c|c|}
\hline & $\begin{array}{c}\mathrm{T} 1 \\
(<0.19 \\
\stackrel{\mu \mathrm{g} / \mathrm{L})}{=}(\mathrm{n})\end{array}$ & $\begin{array}{c}\mathrm{T} 2 \\
(0.19 \mu \mathrm{g} / \mathrm{L}-0.39 \\
\mu \mathrm{g} / \mathrm{L}) \\
(\mathrm{n}=1858)\end{array}$ & $\begin{array}{c}\text { T3 } \\
(>0.39 \\
\mu \mathrm{g} / \mathrm{L}) \\
(\mathrm{n}=1882)\end{array}$ & $\begin{array}{l}\text { Total }(n= \\
5690)\end{array}$ & $p$ \\
\hline Serum Cadmium & $0.12(0.04)$ & $0.28(0.06)$ & \multirow{6}{*}{$\begin{array}{c}0.91(0.73) \\
53.08 \\
(17.49) \\
243.33 \\
(69.1) \\
62.44 \\
(377.94) \\
21.23 \\
(18.67) \\
0.92(0.59) \\
0.44(0.25) \\
42.4\end{array}$} & $0.43(0.54$ & $<0.001$ \\
\hline Age & $34.04(19.77)$ & 48.25 & & $44.98(20.87)$ & $<0.001$ \\
\hline $\begin{array}{l}\text { Platelet count (1000 } \\
\text { cells/uL) }\end{array}$ & $252.5(58.0)$ & $243.93(62.76)$ & & 246 & $<0.001$ \\
\hline $\mathrm{n}$, urine $(\mathrm{ug} / \mathrm{mL})$ & $\begin{array}{c}32.28 \\
(137.51)\end{array}$ & 406.49) & & 48. & 0.016 \\
\hline ALT & $\begin{array}{l}22.01 \\
(16.52)\end{array}$ & $6.01)$ & & $21.63(17.1)$ & 0.37 \\
\hline $\begin{array}{l}\text { Creatinine }(\mathrm{mg} / \mathrm{dL}) \\
\text { Total bilirubin }(\mathrm{mg} / \mathrm{dL}) \\
\text { Male }\end{array}$ & $\begin{array}{c}0.83(0.22) \\
0.47(0.3) \\
59.8\end{array}$ & $\begin{array}{l}0.88(0.42) \\
0.47(0.29) \\
45.6\end{array}$ & & $\begin{array}{l}0.87(0.44) \\
0.46(0.28) \\
49.4\end{array}$ & $\begin{array}{l}<0.001 \\
<0.001 \\
<0.001\end{array}$ \\
\hline $\begin{array}{l}\text { Non-Hispanic White } \\
\text { Liver condition }\end{array}$ & & & & $\begin{array}{l}33.7 \\
4.53\end{array}$ & $\begin{array}{l}<0.001 \\
0.025\end{array}$ \\
\hline Smoked $^{\mathrm{a}}$ & & & & 35.15 & 001 \\
\hline
\end{tabular}

a "Smoked" was defined as ever smoked at least 100 cigarettes in a lifetime

Table 3. Gender differences in association of RBC folate concentration and serum cadmium concentration 


\begin{tabular}{|c|c|c|c|c|c|}
\hline Models & Gender & $\bar{\beta}$-coefficient (95\% CI) & $\begin{array}{c}\mathrm{p} \\
\text { Value }\end{array}$ & $\beta$-coefficient (95\% CI) & $\begin{array}{c}\mathrm{p} \\
\text { Value }\end{array}$ \\
\hline \multicolumn{2}{|c|}{ Tertiles } & \multicolumn{2}{|l|}{ T2 vs. T1 } & \multicolumn{2}{|l|}{ T3 vs.T1 } \\
\hline \multirow{3}{*}{$\begin{array}{l}\text { Model } \\
1\end{array}$} & Total & $21.842(1.561,42.124)$ & 0.035 & $-6.517(-26.539,13.506)$ & 0.52 \\
\hline & Male & $26.78(-4.946,58.506)$ & 0.098 & $-32.067(-64.034,-0.101)$ & 0.049 \\
\hline & Female & $21.949(-4.795,48.693)$ & 0.108 & $10.049(-16.158,36.257)$ & 0.452 \\
\hline \multirow{3}{*}{$\begin{array}{l}\text { Model } \\
2\end{array}$} & Total & $-5.283(-25.053,14.488)$ & 0.6 & \multirow{3}{*}{$\begin{array}{c}-42.649(-62.872 \\
-22.426) \\
-55.182(-87.233 \\
-23.132) \\
-34.71(-60.915,-8.505) \\
\end{array}$} & \multirow{2}{*}{$\begin{array}{c}< \\
0.001 \\
0.001\end{array}$} \\
\hline & Male & $-1.48(-32.964,30.004)$ & 0.927 & & \\
\hline & Female & $-3.882(-29.523,21.758)$ & 0.767 & & 0.009 \\
\hline \multirow{3}{*}{$\begin{array}{l}\text { Model } \\
3\end{array}$} & Total & $-5.345(-25.066,14.377)$ & 0.595 & $-44.05(-64.234,-23.866)$ & \multirow{3}{*}{$\begin{array}{l}< \\
0.001 \\
0.001 \\
0.005\end{array}$} \\
\hline & Male & -2.472 & 0.878 & \multirow{2}{*}{$\begin{array}{c}-54.415(-86.447 \\
-22.384) \\
-37.863(-64.039 \\
-11.688)\end{array}$} & \\
\hline & Female & $-3.241(-28.79,22.307)$ & 0.804 & & \\
\hline \multirow{2}{*}{$\begin{array}{l}\text { Model } \\
4\end{array}$} & Total & $-4.315(-24.168,15.538)$ & 0.67 & \multirow{2}{*}{$\begin{array}{c}-40.683(-62.192, \\
-19.174) \\
-58.941(-94.072,-23.81) \\
-31.371(-58.83,-3.911)\end{array}$} & \multirow{2}{*}{$\begin{array}{l}< \\
0.001 \\
0.001 \\
0.025\end{array}$} \\
\hline & $\begin{array}{l}\text { Male } \\
\text { Female }\end{array}$ & $\begin{array}{l}-3.941(-35.845,27.964) \\
-1.562(-27.192,24.068)\end{array}$ & $\begin{array}{l}0.809 \\
0.905\end{array}$ & & \\
\hline
\end{tabular}

Abbreviations: RBC, red blood cell; CI, confidence interval.

$\beta$ coefficients were interpreted as change of RBC folate concentration for each increase in different serum cadmium concentration.

Adjusted covariates: Model $1=$ Unadjusted model; Model $2=$ Adjusted for age and race/ethnicity; Model 3 = Model $2+$ platelet count, urinary albumin, ALT, total bilirubin, and creatinine; Model $4=$ Model $3+$ history of smoked (defined as ever smoked at least 100 cigarettes in a lifetime).

\section{Figures}


Figure 1.

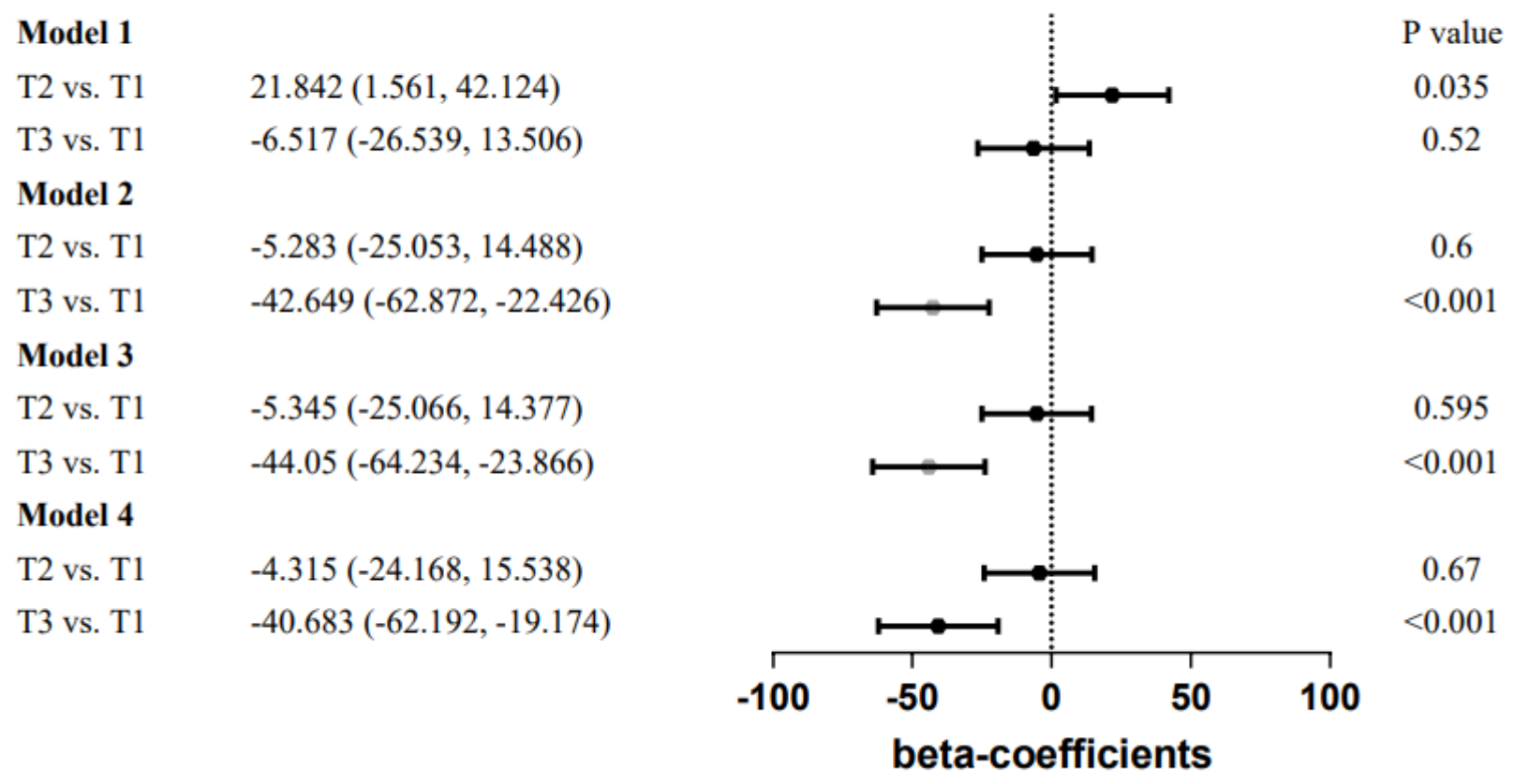

Figure 1

$\beta$-coefficient $(95 \% \mathrm{Cl})$ for RBC folate concentration by tertile of serum cadmium concentration. 